\title{
Infografia: uma revisão bibliográfica sistemática
}

Infographics: a systematic bibliography review

BERNARDES, Marcos; Especialista; UDESC

oi@marcosbernardes.com

SCOZ, Murilo; Doutor; UDESC

muriloscoz@gmail.com

\section{Resumo}

A infografia se popularizou na mídia jornalística, que se utilizou do recurso gráfico a fim de trazer mais atratividade e diferenciação ao conteúdo que até então era predominantemente textual. Porém, seu campo de aplicação vai além disso. Este artigo é uma revisão bibliográfica sistemática com o objetivo de levantar dados a respeito da aplicação da infografia no campo do design e a partir deste levantamento, observar o estado da arte do recurso, suas aplicações e desdobramentos.

Palavras Chave: infografia; infografia interativa; ergonomia cognitiva.

\begin{abstract}
The infographic was popularized at the journalistic media, that used the graphic resource in order to bring more attractiveness and differentiation to the content that until then was predominantly textual. However, its field of application goes beyond that. This article is a systematic bibliographical review aiming to collect data about the application of infographics in the field of design and from this survey, to observe the state of the art of the resource, its applications and unfolding.
\end{abstract}

Keywords: first keyword; second keyword; third and last keyword. 


\section{Introdução}

A revisão bibliográfica sistemática é um caminho coerente a ser traçado no início dos estudos a respeito de uma temática. Em síntese, a revisão é um processo de investigação com delineamentos preestabelecidos que tem como objetivos identificar, selecionar, avaliar e sintetizar os resultados relevantes disponíveis. Desta maneira, uma revisão sistemática deve ser abrangente, e seu processo, assim como os critérios adotados, devem ser registrados e posteriormente divulgados para que outros pesquisadores refazer as etapas.

O campo de aplicação da infografia vem crescendo desde seus primeiros registros, atrelados ao jornalismo. Colle (2004) cita aplicações na área da educação, da ciência, do campo empresarial, entre outros. Além disso, Ribeiro (2008) salienta três plataformas onde a infografia pode ser veiculada: o impresso, o televisivo e o digital.

Ainda neste sentido, autores variados tem definições diferentes a respeito da infografia digital, também chamada de multimídia, interativa e animada (CAIRO, 2008; SANCHO, 2001; RIBAS, 2004). Visando compreender a aplicação da infografia no meio digital e sua relação com os fatores humanos, este artigo executa uma revisão bibliográfica sistemática que engloba infográficos interativos educacionais e o desenvolvimento de métodos que fornecem contribuições para que a interface utilizada durante o processo de leitura seja mais eficiente, eficaz e satisfatória. Neste sentido, a utilização de heurísticas pode ser um possível método da avaliação destas interfaces, visando encontrar os problemas de utilização de infográficos interativos.

A pesquisa, além de buscar resultados que comprovam a relevância no assunto, também serve para compreender aspectos particulares do recurso, que são indispensáveis na construção do método.

\section{Fundamentação teórica}

O capítulo de fundamentação teórica serve como uma base elementar para qualquer estudo científico. A função deste tópico é alicerçar a pesquisa com base na ideia de outros autores encontrados durante a revisão de textos, artigos, livros, periódicos ou todo material que tenha relevância ao assunto pesquisado. Para Beuren (2003), o pesquisador deve se familiarizar com pesquisas anteriores na área antes de fazer delimitações do seu próprio trabalho. Neste sentido, a fundamentação teórica encontrada neste artigo é uma síntese da conceituação e história da infografia, que oferece uma breve visão a respeito do assunto.

\subsection{Infografia: conceitos e definições}

Os Há diversos conceitos que definem infografia, embora grande parte dos pesquisadores na área fazem uma associação direta da infografia a mídia jornalística. Parte disso, se dá pelo fato de que este meio de comunicação vem se utilizando da infografia como diferencial competitivo e estético, a fim de atrair novos leitores ou deixar seu conteúdo mais atrativo. Porém, outras áreas tem se beneficiado com este recurso, como a educação, o mercado editorial, os meios digitais, entre outros.

Para compreender melhor seu conceito, parte-se do próprio significado da palavra. Ribeiro 
(2008) cita que a expressão vem do termo inglês infographic, que por sua vez é uma redução de information graphics, e quando traduzido para português significa informação gráfica. Moraes (2013) defende que a infografia pode ser entendida como um esforço de apresentar, de maneira clara, informações complexas o bastante para serem transmitidas apenas por textos. Cairo (2008), outro pesquisador da área, compreende infografia como uma representação diagramática de dados.

Teixeira (2010) acredita que infografia é entendida como uma modalidade discursiva na qual há presença indissociável de imagem e texto em uma construção narrativa que permite a compreensão de um fenômeno específico ou funcionamento de algo complexo. A autora ainda faz uma classificação dos infográficos, dividindo-os em duas categorias, os jornalísticos e os enciclopédicos. Os jornalísticos são relacionados àqueles que geralmente aparecem na imprensa (jornais e revistas) e narram fatos específicos ou noticiosos, já os enciclopédicos, são centrados em explicações de caráter mais universal como por exemplo, detalhes do funcionamento do corpo humano, o que são bactérias ou como se formam as nuvens.

Segundo Caixeta (2005), em seu artigo para o website da ABI - Associação Brasileira, a infografia é uma forma de representar informações técnicas como números, mecanismos e/ou estatísticas, que devem ser sobretudo atrativos e transmitidos ao leitor em pouco tempo e espaço. Normalmente utilizado em cadernos de saúde ou ciência e tecnologia, em que dados técnicos estão presentes, o infográfico vem atender a uma nova geração de leitores que é predominantemente visual e quer entender tudo de forma prática e rápida.

Schmitt (2006) define infografia como um sistema híbrido de comunicação, pois ao empregar imagens, palavras e números, utiliza um sistema de comunicação verbal (palavras e sentenças) e visual (imagens e representações gráficas).

Para Raymond Colle (2004) os campos de aplicação e estudo da infografia vão além da mídia jornalística e podem ser divididos em: manuais de usuários, onde os infográficos inseridos nos manuais tem como objetivo auxiliar ou esclarecer as operações que o usuário irá desenvolver; Informes empresariais, que tratam das operações da empresa ou instituição; infografia pedagógica, presente em manuais, livros e enciclopédias ligadas à educação; infografia publicitária, presente na publicidade, como seu próprio nome sugere; infografia técnica, baseada na simples associação e/ou integração de desenho e texto e encontrada em textos científicos ou manuais técnicos; infografia jornalística, encontrada frequentemente na mídia jornalística.

Suzana Ribeiro (2008) também classifica infografia dividindo-a em três categorias diferentes: a infografia impressa, que abrange todos os meios com o suporte de papel, como jornais, revistas, livros, entre outros; a infografia online, que tem ganhado espaço devido ao desdobramento das mídias impressas ao digital e a criação de novas plataformas capazes de suportar e/ou informar através de infográficos digitais; e por fim, a infografia televisiva. Sancho (2001) defende que o infográfico é composto por vários infogramas, que por sua vez são como unidades mínimas de informação gráfica, como um texto, um ícone, uma fotografia, um mapa ou uma ilustração, e estes infogramas podem formar um infográfico.

Apesar do conceito ser variado, na questão do objetivo, pode-se entender com base nos autores pesquisados que o infográfico tem como função principal facilitar a comunicação, possibilitar com que o leitor tenha a compreensão do texto ampliada, permitir uma visão geral dos acontecimentos e detalhar informações menos familiares ao público, sendo assim, o conteúdo tem 
explicações em diversos níveis de complexidade, como apresentação de fatos ou acontecimentos, informações de funcionamento, descrição de procedimentos ou métodos.

Raymond Colle (1998) acredita que a infografia é um recurso que utiliza linguagem visual e verbal, mesclada com códigos icônicos a fim de oferecer informações amplas e precisas, que seriam mais complexas de ser entendidas caso fossem explicadas somente através de um discurso verbal e a forma de apresentação desse conteúdo pode ser variada, como mapas, esquemas, catálogos, entre outros.

Diante disso vale lembrar o relato apresentado por Moraes (2013) quando se referia a história da mídia impressa no Brasil. Apesar do mapas, gráficos estáticos, caricaturas e infográficos já fazerem parte do repertório de jornais nos anos de 1880, na década seguinte a utilização destes recursos foi abrangente, principalmente em jornais populares. Supostamente, este recurso ajudaria aqueles que não tinham a prática de leitura diária tão desenvolvida quanto os leitores de elite e portanto, seguindo este raciocínio, os infográficos executavam a função de fazer a mediação entre a informação jornalística e o público.

Com base nos autores citados no texto, compreende-se então que a infografia é um recurso que se utiliza de linguagem verbal e visual com o objetivo de transmitir uma informação de maneira mais clara e eficaz. Entretanto alguns autores sugerem que o infográfico deve conter algumas características para efetuar sua função com eficácia e precisão. Para Edward Tufte (2001) um infográfico deve primeiramente mostrar dados.

Além disso, a infografia deve conduzir o leitor ao ato de pensar acerca do conteúdo informado, sem que ele se atenha ao desenho gráfico, a tecnologia da produção gráfica, ou qualquer outro item que possa desviar a atenção, além de evitar distorcer a informação que se propõe a transmitir. O recurso deve apresentar grandes quantidades de informação e mesmo assim manter a coerência, revelar a informação se utilizando do que autor chamada de camadas ou hierarquias e fazer com que o leitor percorra desde as camadas mais superficiais até as de estruturação. 0 infográfico deve integrar suas informações verbais e estatísticas em um grupo coeso de dados e por fim, exercer sua função de transmitir um conteúdo com descrição, clareza, explorando aspectos estéticos e/ou decorativos.

Outro autor que também aborda características que devem englobar um infográfico é Valero Sancho. Para ele (2001), a infografia quando aplicada no jornalismo impresso deve proporcionar informações suficientes para a compreensão do conteúdo, sugerir uma ordem de leitura e utilizar de recursos gráficos para isso. Para o autor é relevante que o infográfico realize uma síntese ou uma complementação do informação verbal, se utilizando, quando necessário de elementos icônicos, sem deturpar o conteúdo. Finalmente, o infográfico deve ser preciso e exato e proporcionar uma configuração estética.

\section{Revisão bibliográfica}

Segundo Dane (1990), a revisão bibliográfica é importante pois define uma linha confinante da pesquisa a ser desenvolvida, portanto é preciso definir termos, autores, palavras-chave e fonte de dados que serão fundamentais para a tarefa. Para Cook et al (1997) e Cooper (1998) a pesquisa de revisão sistemática é relatada como metódica, transparente e replicável. Cook et al (1997) salienta ainda que uma revisão sistemática é baseada na aplicação de métodos com maior rigor 
científico, e desta maneira é possível obter resultados mais específicos e reduzir erro. Através deste processo o pesquisador compila os dados, têm uma compreensão mais ampla a respeito do assunto pesquisado e assim pode apurar hipóteses, estabelecer a amostra ou definir direcionamentos para futuras pesquisas (COOK et al., 1997).

Desta maneira a revisão sistemática se estabelece como um passo inicial para qualquer pesquisa científica (WEBSTER; WATSON, 2002), podendo ser concebida com base em materiais já elaborados, como livros, artigos, teses e dissertações (GIL, 2007). Gil (2007) acrescenta ainda que a revisão bibliográfica possui um caráter exploratório, pois possibilita que o pesquisador tenha maior proximidade com o problema e por consequência aprimore suas ideias.

Sob o mesmo ponto de vista, o presente artigo utiliza o referencial obtido na pesquisa bibliográfica em base dados com o objetivo de detectar o estado da arte da literatura e desta forma observar o que existe de conformidade e controverso a respeito do objeto de pesquisa.

Em vista disso, uma revisão bibliográfica foi efetuada tendo a Scopus como principal base de dados. A pesquisa se dividiu em três etapas com desdobramentos, e em cada uma delas o critério de relevância e escolha dos resultados finais levaram em consideração um futuro estudo que engloba heurísticas e infografia interativa. A priori foram utilizados termos mais amplos, com o propósito de ter uma vasta visão do objeto e sua área de conhecimento. Em virtude disso foram aplicados os termos "graphic design" e "information design", alcançando 3.978 resultados. Posteriormente a pesquisa se limitou aos resultados ligados à ergonomia e à área de ciências sociais, obtendo 184 e 65 resultados respectivamente. Tendo em vista que os resultados ainda eram abrangentes e demasiadamente grande para ser revisado, foram combinados os termos "interaction", que logrou 14 resultados, e por fim "data visualization", obtendo 5 resultados, dos quais somente 1 se encaixava nos objetivos da pesquisa.

A segunda pesquisa foi efetuada com termos menos amplas, abordando diretamente palavras-chaves de relação estreita com a pesquisa. A pesquisa se iniciou com o "interactive infographics", obtendo 24 resultados. Em seguida o termo "data visualization" foi adicionado, alterando o resultado para 11 . Com o intuito de estreitar a pesquisa e deixá-la mais efetiva, as palavras-chave "infographics" e "visualization" foram adicionadas, obtendo assim 7 resultados, dos quais 2 deles foram considerados relevantes para a pesquisa.

Finalmente, na terceira etapa da pesquisa foram separados os termos "infographics" e "interactive", com um filtro para as áreas de ciências sociais e ciências da computação, obtendo 17 resultados. Logo após foi combinado o termo "heuristics", termo também relevante para a pesquisa. O resultado foram 2 artigos, sendo que 1 deles já havia sido encontrado na primeira etapa da pesquisa.

\subsection{Classificações e especificidades das dimensões da infografia}

"Static and interactive infographics in daily tasks: A value-in-use and quality of interaction user study." Angela Locoro, Federico Cabitza, Rossana Actis-Grosso, Carlo Batini Computers in Human Behavior, n. 71 - 2017

O artigo pesquisado é uma investigação exploratória acerca de como pessoas leigas, com diferentes perfis de idade, gênero ou grau de instrução, concebem o uso de infográficos para a orientação e visualização de tarefas diárias. No estudo, as pessoas interagiram com infográficos 
feitos a partir de tópicos considerados de interesse geral: clima, estudo é trabalho.

Com o propósito conceituar infografia e suas classificações, o artigo se baseou em Lanlow, Ritchie e Crooks (2012) que tipificam infográficos em três categorias: estático, interativo e de movimento. A infografia estática é uma imagem fixa (SEGEL \& HEER, 2010); o infográfico interativo se refere a possibilidade de interagir com o recurso, atualizando e variando determinados parâmetros (BETRANCOURT, TVERSKY, 2000; BRUCKER, SCHEITER, GERJETS, 2014; TVERSKY, MORRISON, BETRANCOURT, 2002); e por último, o infográfico de movimento se trata de um infográfico que utiliza recursos multimídia e multimodais para apresentar seu conteúdo. Dentre estes recursos estão a música, curta-metragem, entre outros.

Apesar do estudo esclarecer a existência destas três classes, o mesmo engloba somente as versões estática e interativa para maior difusão. Os infográficos estáticos foram gerados a partir de uma imagem fixa dos infográficos interativos, isso cria condições de comparação, mas ao mesmo tempo possibilita criar condições diferentes para o experimento.

Aos participantes do experimento foi permitido julgar a qualidade dos infográficos referente a sua informação, sua interação e seu design. Enquanto isso, os avaliadores mediam o esforço mental requerido durante a tarefa de interação e o valor de uso das informações dispostas na infografia. Desta maneira, a maior contribuição deste estudo é o acesso à dimensões de qualidade complementares da experiência do usuário durante a interação com infográficos estáticos ou interativos.

As dimensões abordadas pelo estudo são a qualidade da informação e interação e a qualidade do design. Estas dimensões servem de embasamento teórico para as questões que foram apresentadas aos participantes do experimento, além de gerar classificações para cada uma das características da infografia.

Para o item qualidade da informação e interação foram utilizadas as seguintes dimensões: sintetização, clareza, informatividade, intuitividade, elegância, atratividade, usabilidade e facilidade no uso, sendo que diversos autores foram utilizados para gerar a definição de cada um destes aspectos.

Para as dimensões de qualidade do design foi utilizado The Visualization Wheel, em tradução livre, o círculo da visualização (CAIRO, 2012), que trata de um gráfico que aborda características subjetivas de uma infografia divididas em dois hemisférios: a parte superior relativa a aspectos mais complexos e profundos, bem como a quantidade de esforço que o leitor dispensa para decifrar um gráfico, e a parte inferior, voltada para aspectos mais superficiais e de fácil assimilação (Figura 1).

Cada um dos eixos do círculo possui um elemento oposto no hemisfério antagônico, sendo eles: a abstração / a figurativização, a funcionalidade / a decoração, a densidade / a leveza, a multidimensionalidade / a unidimensionalidade, a originalidade / a familiaridade e a essencialidade / a redundância.

Para o desenvolvimento da pesquisa foram criados questionários contendo 3 perguntas abertas, utilizadas tanto para o recurso estático, quanto para o interativo, além de perguntas relacionadas a qualidade dos itens de interação e qualidade do design. Para estas foi utilizada a escala likert. A amostra contou com aproximadamente 350 participantes que foram divididos em dois grupos de maneira aleatória. Um grupo interagiu com o infográfico interativo, enquanto o outro interagiu com o infográfico estático. 
Figura 1 - O círculo da visualização

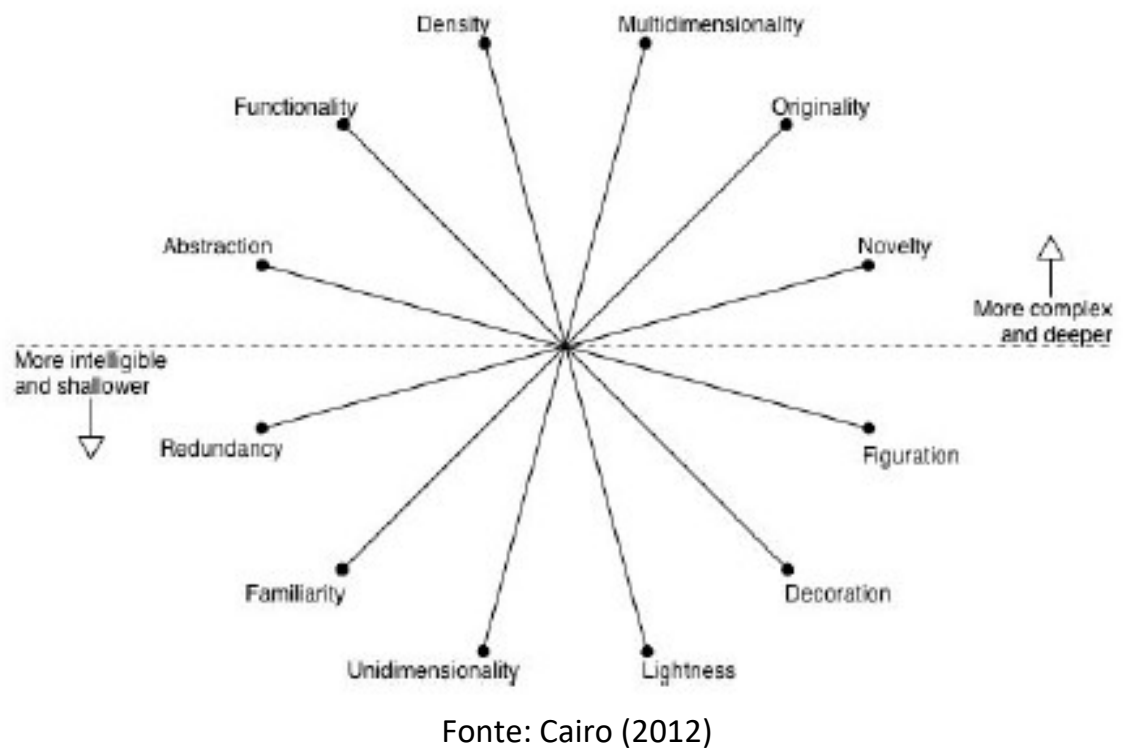

O que foi observado no término do estudo é que os usuários expressaram uma clara preferência pelos infográficos interativos, e em particular com as temáticas clima e estudo. Uma importante contribuição que o artigo traz para os estudos relacionados a infografia é a proposta de um modelo de avaliação de diferentes qualidades e aspectos de infográficos estáticos e interativos.

\subsection{Classificações e especificidades das dimensões da infografia}

"Infografía: etapas históricas y desarrollo de la gráfica informativa" Roberto Gamonal Arroyo, Historia y Comunicación Social, n. 18 - 2013.

O artigo realiza um passeio histórico da evolução dos infográficos. Apesar de ser uma disciplina de estudo moderna e o termo ter sido utilizado pela primeira vez no final da década de 1980, o artigo aborda inúmeros precedentes da necessidade humana de utilizar dados sintetizadas ou transformadas em códigos visuais para facilitar a compreensão de uma informação.

A pesquisa revela que a exibição de dados e informações através de uma linguagem gráfica não responde somente a uma história recente, ligada ao desenvolvimento tecnológico e tudo o que ele proporciona, mas a um modelo de pensamento predominante que se pode ser exemplificado em outros momentos da história.

De acordo com Grombrich (1990) a imagem sempre fez parte da história. Neste sentido ele cita que representações pré-históricas de cenas de combate respondiam a um propósito de aprender com a realidade. Da mesma forma, gregos e romanos faziam suas representações usando cânones que buscam a perfeição é beleza divina.

Historicamente o homem produz uma diferença entre o mundo real, criado pelos seres humanos, e o mundo criado por uma divindade. Um exemplo disso pode ser visto no mapa de Ptolomeu, do século II, onde a terra é cercada de anjos tocando suas trombetas.

O trabalho ainda cita que a criação de representações gráficas auxiliava na compreensão de 
uma história ou acontecimento, levando em consideração que mesmo na idade média a maioria da população não sabia ler e a leitura só era possível em atos religiosos onde o sacerdote lia os textos sagrados.

$\mathrm{Na}$ Renascença ocorre uma mudança no pensamento e compreensão das coisas, impulsionada pelos avanços científicos e tecnológicos. Este é um período em que o teocentrismo cede lugar para o antropocentrismo e há uma busca pela explicação das coisas que antes eram creditadas à divindades. $\mathrm{O}$ ser humano encontra na natureza formas geométricas e proporções que até então não eram percebidas e se utiliza da natureza como uma fonte de inspiração para criar coisas novas.

Com o conhecimento em expansão, a igreja já não detém o conhecimento e as pessoas têm mais acesso à livros e universidades. Neste momento a reprodução impressa multiplica exponencialmente o conhecimento, proporcionando o progresso científico de disciplinas como medicina, ciências sociais, biologia, zoologia e botânica, que necessitava de ilustrações para auxiliar na transferência de conhecimento.

A imagem se torna um instrumento de difusão de ensino e cultura. Para José Luis Valero (2001), os afrescos da Capela Sistina são um exemplo disso. O objetivo era criar uma explicação visual acerca da criação é julgamento para que o público analfabeto. Outro exemplo é Leonardo da Vinci, que se utilizava de representações gráficas para compartilhar o conhecimento científico.

Sheila Pontis (2007) cita que entre os séculos XVI e XVII importantes para o desenvolvimento da representação gráfica como uma forma dar apoio ao conhecimento teórico verbal. Segundo ela, isso se refletiu nas enciclopédias e dicionários que reuniam o conhecimento de diversas áreas do conhecimento e eram amplamente ilustrados. Como exemplos, pode-se citar a L'Encyclopédie ou o Dictionnarie Raisonné des Sciences, publicados entre 1751 e 1772, que ao todo somavam 33 volumes com 2.900 ilustrações.

De acordo com Valero (2012), a primeira vez que um jornal se utilizou de uma imagem foi em 1702, no The Daily Courant. A imagem era um mapa da Baía de Cádiz e contava detalhes a respeito do conflito com os britânicos durante o reinado de Felipe $\mathrm{V}$.

Ainda neste sentido, para Peltzer (2001) o primeiro infográfico foi publicado pelo The Times em 1806 e explicava um assassinato com detalhamento. No mesmo jornal foi registrado o primeiro mapa do tempo, em 1875.

Outro marco na história da visualização de dados foi criada por Willian Playfar. O economista começou a usar gráficos de linha, diagramas de barra, entre outros para representar dados econômicos. Muitos dos gráficos criados por Playfar são utilizados até hoje.

O artigo também relata formas importantes de visualização de dados, como o gráfico criado por Charles Joseph Minard, que explicava de maneira didática a campanha militar de Napoleão Bonaparte durante a invasão da Rússia em 1812; o sistema Isotype, projetado por Otto Neurath e ilustrado por Gerd Arntz, que objetivava comunicar através de uma linguagem não-verbal, baseada em um sistema de pictogramas icônicos universais; e o mapa do metrô de Londres, criado em 1933 por Henry Beck, que não se baseava na geografia da cidade, mas buscava transmitir de forma simples a informação espacial através de um esquema formada por linhas geométricas e variação de cores.

Mais adiante, com o surgimento da internet, houve um crescimento exponencial na 
quantidade de informação disponível e com isso, fez-se a necessidade de profissionais cuja o objetivo era organizar, fazer sentido e apresentar esse conteúdo de forma atrativa, sistemática, compreensível e coeso (CAIRO, 2011).

O avanço da tecnologia, a criação de softwares de edição gráfica, programação e animação permitem criar meios mais eficazes de visualizar dados. Os Infográficos então deixam de ser aplicados exclusivamente na mídia impressa e acontecem também nas telas, combinando recursos audiovisuais, animações, entre outros com o objetivo de criar mais interatividade. $\mathrm{O}$ usuário tem a opção de ter sua própria experiência de leitura.

Um exemplo deste modelo interativo é o gráfico de 2013 que explicava o ataque ocorrido na maratona de Boston. Nele, o usuário tinha a possibilidade de compreender os pontos da perseguição policial para pegar os responsáveis através da interatividade com o Google Maps. O usuário podia ampliar a visualização do mapa ao ponto de ver as ruas, como se estivesse no local.

Outra mudança profunda com a utilização de infográficos interativos é a possibilidade do usuário interagir com estes dados. Desta forma a construção da informação não é mais um território exclusivo do jornalista e fica aberto a qualquer cidadão agir mutuamente com o conteúdo, seja na construção ou visualização dos dados.

O artigo cita como exemplo o projeto "España em Ilamas", criado por Juan Elosua. O projeto é um gráfico que apresenta os incêndios florestais acontecidos na Espanha entre 2001 à 2011. Dados como: o número de incêndios, quantos hectares foram perdidos, a quantidade de feridos e mortos e os prejuízos foram apresentados de maneira visual, possibilitando uma leitura sintetizada e clara.

\subsection{O impacto da infografia como ferramenta de educação}

"Statistical reasoning of impact of infographics on education" Fezile Ozdamli, Senay Kocakoyun, Turker Sahin, Sahin Akdag, Procedia Computer Science, n. $102-2016$.

Com o avanço contínuo da tecnologia na era da informação, o ensino e o aprendizado são estimulados a se adequar tanto nos métodos aplicados, quando nas abordagens utilizadas em sala de aula. Esse avanço força educadores e instrutores a reformular práticas e técnicas já consagradas na educação.

A tecnologia então passa a ser uma ferramenta instrucional e uma possibilidade na tarefa de reformulação do material didático e das práticas do ensino. Neste sentido, a tecnologia também reacende questões a respeito de como ensinar, quais habilidades o professor deve ter para utilizar as tecnologias, como enriquecer a para o material didático a fim de auxiliar na transferência de informação e no processo de aprendizagem. Em outras palavras, a visualização de informação é um método que permite de maneira visível, cria significado na mente do aluno, que pode configurar, organizar e editar informações durante processo de aquisição de conhecimento.

Borkin et al (2013) estudaram os tipos de visualização e seu relacionamento com o nível de memória. Para eles, materiais informativos que contém pictogramas, mapas ou gráficos são mais lembrados do que informação totalmente textuais.

Neste caso, o infográfico pode ser compreendido com um material útil na transferência de informação, mesmo quando o conteúdo tem informação demasiadamente grande ou complexa. Este estudo analisa as percepções dos estudantes em relação a um conteúdo transmitido no 
formato de infografia. Assim sendo, 140 (130 homens e 10 mulheres) estudantes da disciplina de anatomia do curso de Educação Física e Departamento de Esportes da Near East University participaram da pesquisa.

O infográfico utilizado para o experimento tinha como temática o sistema do aparelho digestivo e o conteúdo foi inserido durante o semestre letivo. Vale lembrar que a aplicação do estudo na disciplina de anatomia se deu pois segundo o estudantes, o conteúdo envolvido é difícil de memorização e compreensão.

Além de examinar a percepção dos alunos a respeito de um conteúdo apresentado como infografia, o estudo ainda visa entender a relação dos alunos com o recurso. Desta forma, após o contato com o conteúdo, o aluno era submetido a um questionário para saber se ele já conhecia infografia; se achavam que era um recurso vantajoso em relação à outros recursos aplicados na educação; se o mesmo ajudou a compreender o assunto; o que achavam sobre infografia; quais as vantagens e desvantagens da infografia; entre outras perguntas.

O resultado da pesquisa mostrou que dentre os participantes, 38,6\% (54 estudantes) já tinham visto um infográfico antes e $61,4 \%$ (86 estudantes) nunca tiveram qualquer contato com o meio.

Quando questionados a respeito das vantagens da infografia comparado a outras maneira expositivas utilizadas em sala de aula, $58,6 \%$ (82 estudantes) responderam que sim, enquanto $38,6 \%$ (54 estudantes) disseram não ter certeza e 2,8\% (4 estudantes) responderam que não.

Além disso, quando indagados se o infográfico os ajudou a compreender melhor o assunto, $86,4 \%$ (121 estudantes) disseram que sim, 5,7\% (8 estudantes) disseram não ter certeza é 7,9\% (11 estudantes) responderam que não. Outra pergunta foi o que os estudantes acharam sobre infografia. As respostas pré disponibilizadas diziam respeito a visão positiva, negativa ou neutra que os estudantes tinham no tocante ao infográfico. Neste item, 75,7\% (106 estudantes) declararam ter uma visão positiva, 4,3\% (6 estudantes) revelaram uma visão negativa e $20 \%$ ( 28 estudantes) não tinham certeza da visão que tinham sobre infografia.

No momento em que foram questionados sobre as vantagens da infografia, $29,3 \%$ (68 estudantes) declararam que infográficos foram mais explicativos do que descrições textuais. $16,4 \%$ (23 estudantes) asseguraram que o aprendizado os conteúdos apresentados em forma de infográfico são mais fáceis de serem memorizados e 10,7\% (15 estudantes) acham que o conteúdo se torna mais compreensivo. A quantidade de participantes que consideraram a pesquisa em infográficos mais confortável foi de 4,3\% (6 estudantes). Inesperadamente, mesmo que nas questões anteriores a visão dos participantes em relação a infografia seja positiva, 39,3\% (55 estudantes) não tinham um posicionamento claro ou não sabiam descrever as vantagens do recurso no ensino.

Finalmente, na questão acerca das desvantagens da infografia, 48,5\% (68 estudantes) asseguraram não haver desvantagens no método. Todavia, 5\% (7 estudantes) declararam que as apresentações via infografia foram mais rápidas que as convencionais e portanto ficou mais difícil de assimilar a informação. 39,3\% (55 estudantes) foi a proporção dos que não tinham posicionamento claro a respeito das desvantagens do recurso. 4,3\% (6 estudantes) dos participantes acharam que as apresentações com infografia ficaram confusas e por fim, 2,9\% (4 estudantes) acreditavam que as aulas com infografia eram perda de tempo. 
O estudo mostrou que em geral, os estudantes não conheciam muito a respeito de infografia, porém, em sua maioria, se mostraram satisfeitos quanto às possibilidades da ferramenta e o modo com que as aulas foram apresentadas. Neste sentido, a maioria dos estudantes teve uma visão positiva a respeito do infográfico e se mostrou disposta a estudar com um conteúdo em formato de infografia. Finalmente, o estudo aponta que há vantagens significativas na aplicação do recurso como uma forma de dinamizar os métodos de aprendizagem.

\subsection{Heurísticas cognitivas e a influência no modo como os indivíduos tomam decisões}

"Information Graphics and Intuition: Heuristics as a Techne for Visualization" John Jones, Journal of Business and Technical Communication - 2015.

Estudos acerca da comunicação criticam a ideia de que estilos visuais derivados de teorias cognitivas podem ser entendidos por qualquer pessoa e efetivo em qualquer tipo de comunicação. A aplicação indiscriminada das teorias do design baseadas em pesquisas perceptivas tem sido criticada quando aplicada em visualização de dados, pois tendem a ignorar os contextos nos quais são criadas em favor de sucessão de regras de estilo, como utilizar o mínimo de cores (TUFTE, 2001), ou fazer com que a parte gráfica seja o mais sútil possível (TUFTE, 1997). Regras gerais baseadas baseadas na cognição e percepção (KOSTELNICK, 2008).

Diante disso, surge uma pergunta: como aplicar o resultado de pesquisas cognitivas em um processo de design retórico? Em resposta à esta pergunta, profissionais de comunicação creem que melhor do que universalizar as abordagens estilísticas, designers devem explorar características particulares de situações retóricas (KOSTELNICK, 2008). Um meio potencial de abordar esta questão pode ser a teoria das heurísticas e vieses, introduzida pelos psicologistas Amos Tversky e Daniel Kahneman.

A teoria afirma que indivíduos tendem a escolher por atalhos mentais durante a formação de julgamentos intuitivos e estes julgamentos, por sua vez podem ser tendencioso, fornecendo soluções enganosas. Além da psicologia, outros campos adotaram as heurísticas.

O artigo aponta que heurísticas são componentes ideias para uma abordagem retórica do design por que levam em conta o processo perceptivo. As heurísticas e vieses sustentam que quando um indivíduo se depara com um problema que tem uma resposta incerta ou inacessível, seu processo intuitivo gera uma solução substituindo um resultado conhecido por outro incerto (KAHNEMAN, FREDERICK, 2002). Como complemento, esta resposta intuitiva é baseada em um modelo mental no qual a tomada de decisão é controlada por dois sistemas paralelos do cérebro, referenciados como sistema 1 e sistema 2.

O modelo de pensamento argumenta que o sistema 1 gera respostas rápidas e inconscientes enquanto o sistema 2, mais lento e analítico, avalia as respostas. As pesquisas a respeito de heurísticas e vieses têm utilizado as interações entre estes dois sistemas para definir três amplas categorias de substituição de atributos das heurísticas: representatividade, disponibilidade e afeição (KAHNEMAN, FREDERICK, 2002).

As heurísticas de representatividade substituem atributos que são similares. Neste sentido os atributos em questão podem ser substituídos por outros mais simples ou que têm relações entre si. Como exemplo, indivíduos podem avaliar a probabilidade de um evento "B" levando em 
consideração que um evento " $A$ " se assemelhe ao evento " $B$ ". Em outras palavras a representatividade é a tendência de se utilizar estereótipos para fazer julgamentos.

Ora, as heurísticas de disponibilidade substituem um determinado atributo por um que seja mais lembrado e que ocorre mais em sua mente. Como exemplo, um indivíduo pode cogitar a probabilidade de uma pessoa jovem ter problemas cardíacos relembrando quantos casos parecidos ocorreram com pessoas do seu convívio.

Assim também, as heurísticas de afeto substituem os atributos com sentimento de positividade ou negatividade, como quando a avaliação de uma pessoa a respeito do conteúdo de uma mensagem impressa, escrita com a tipografia Comic Sans é anulado por um sentimento de negatividade por causa deste tipo de letra. Em síntese, estas heurísticas estão relacionadas com as qualidades boas ou ruins que são atribuídas a determinadas experiências.

Assim, o presente artigo sugere que estas heurísticas cognitivas provêm uma estrutura para conciliar as características de visualização com as características culturais e contextuais de retóricas particulares, analisando infográficos nas heurísticas de representatividade, disponibilidade e afeição.

$\mathrm{O}$ artigo analisa quatro infográficos, tendo como base as heurísticas e vieses, além disso, o estudo faz uma paralelo entre as preocupações do design influenciadas pelas heurísticas. Para o autor, representatividade está associado a familiaridade e provê suporte para o esforço cognitivo à projetos desconhecidos ou em condições restritas. A disponibilidade, por sua vez, está ligada à simplicidade e provê contexto para comparação, além de evitar erros. Por fim, a heurística de afeto, remete à emoção é objetividade e provê um nível de contexto emocional para a expectativa emocional da audiência.

Ao se unir pensamento contextual e emocional com percepção e intuição, as heurísticas de representatividade, disponibilidade e afeto podem servir como embasamento para uma técnica de design estratégico que fornece aos designers uma estrutura para respostas perceptuais e intuitivas de visualização dentro de uma estrutura de infográfico.

\section{Conclusão}

Os artigos analisados demonstram o estado da arte da infografia. A revisão sistemática abordou pontos importantes que servem como embasamento científico para a futura pesquisa que engloba infografia interativa, infografia educacional e heurísticas. Neste sentido, o primeiro artigo resumido nesta revisão, que aborda a comparação entre a utilização de infográficos estáticos e interativos, traz avanços consideráveis para a pesquisa, pois trata dos atributos da qualidade da informação e interação e qualidade do design em infográficos. As dimensões de qualidade abordadas no artigo servem de base para a categorização de infográficos, necessária no futuro estudo.

A revisão também aborda de maneira mais abrangente a história da infografia, examinando os primeiros indícios da infografia, antes mesmo desse termo ter sido empregado. A revisão histórica auxilia na compreensão do recurso e principalmente, da sua funcionalidade. A escolha pela utilização, independente do momento histórico, é sempre amparada pelas necessidades dos leitores. Ora a escolha se dá pela pouco agilidade dos leitores com grandes blocos de texto, levando 
em conta um período em que alguns leitores eram iletrados ou pouco habituados com leitura. Ora se dá pelo avanço tecnológico, possibilitando que jornais, revistas e outros meios de leitura utilizem ilustração, fotos ou outros recursos para criar diferencial competitivo e atratividade. Em outros momentos a infografia é aplicada devido a necessidade de dinamismo e interatividade na informação. Novamente amparado pelas novas tecnologias ou novos hábitos dos leitores.

Ainda neste sentido, a revisão sistemática mostra a utilização da infografia na educação e sua potencialidade como ferramenta de aprendizagem, corroborando com a ideia de que a apresentação de informações utilizando gráficos, textos e/ou outros recursos tem maior pregnância do que informações integralmente textuais, como comprovado no estudo.

Por fim, a revisão apresenta um resultado que engloba infografia interativa e heurística, o que é positivo para o futuro estudo, levando em consideração que as heurísticas utilizadas no estudo não são específicas para interfaces digitais, desta forma é possível constatar o ineditismo da pesquisa a ser desenvolvida e sua contribuição para os estudos acerca de infografia digital interativa.

\section{Referências}

ARROYO, Roberto G. Infografía: etapas históricas y desarrollo de la gráfica informativa. Madrid: Historia y Comunicación Social, 2013.

BEUREN, Ilse M. Como elaborar trabalhos monográficos em contabilidade. Teoria e prática. São Paulo: Atlas, 2003.

BETRANCOURT, M.; TVERSKY, B. Effect of computer animation on users' performance: A review. Le Travail Humain, 63(4), 2000.

BRUCKER, B.; SCHEITER, K.; GERJETS, P. Learning with dynamic and static visualizations: Realistic details only benefit learners with high visuospatial abilities. Computers in Human Behavior, 36, 2014.

CAIRO, A. Infografia 2.0: visualización interactiva de información em prensa. Madrid: Alamut, 2008.

CAIRO, A. El arte funcional. Infografía y visualización de información. Madrid: Alamut, 2011.

CAIRO, A. The Functional Art: An introduction to information graphics and visualization. New Riders, 2012.

CAIXETA, R. A arte de informar. Jornalismo na prática: A arte de informar, 2005.

COLLE, R. Estilos o tipos de infógrafos. Revista Latina de Comunicación Social. La Laguna (Tenerife), n. 12, dez, 1998. Disponível em: <http://www.revistalatinacs.org/a/02mcolle/colle.htm >. Acesso em: 22 nov. 2017. 
COLLE, R. Infografia: tipologias. In: Revista latina de comunicación social, 58, 2004.

FERRERES, G. La infografía periodística. In: Intachina: Docs, 1995.

COOK, D. J.; MULROW, C. D.; HAYNES, R. B. Systematic reviews: synthesis of best evidence for clinical decisions. Annals of Internal Medicine, v.126, n.5, 1997.

COOPER, H. Synthesizing Research. Thousand Oaks: Sage, 1998.

DANE, F. Research methods. Brooks/Cole Publishing Company: California, 1990.

DE PABLOS, Jose M. Infoperiodismo. El Periodista como Creador de Infografia. Madrid: Editorial Sintesis, 1999.

OZDAMLI F.; KOCAKOYUN S.; SAHINA T.; AKDAGA S. Statistical reasoning of impact of infographics on education. Lefkosa: Procedia Computer Science. Lefkosa, 2016.

Gil, A. Como elaborar projetos de pesquisa. Atlas: São Paulo, 2007.

KANNO, M. Infografe. Como e porque usar infográficos para criar visualizações e comunicar de forma imediata e eficiente. São Paulo: Infolide.com, 2013.

JONES, J. Information Graphics and Intuition: Heuristics as a Techne for Visualization. Morgantown: Journal of Business and Technical Communication, 2015.

LANKOW, J.; RITCHIE, J.; CROOKS, R. (2012). Infographics: The power of visual storytelling. John Wiley \& Sons, 2012.

LOCORO, A.; CABITZA F.; ACTIS-GROSSO R.; BARTINI C. Static and interactive infographics in daily tasks: A value-in-use and quality of interaction user study. Computer in Behavior Human, 2017

MORAES, A. Infografia. História e Projeto - Origens, conceitos e processos do design que modificou a forma da mídia mais tradicional da História. São Paulo: Blucher, 2013.

RIBAS, B. Infografia Multimídia: um modelo narrativo para o webjornalismo. [Consultado em junho de 2017] Disponível em: http://www.facom.ufba.br/jol/pdf/2004_ribas_infografia_multimidia.pdf, 2004.

RIBEIRO, S. A. Infografia de Imprensa: História e análise ibérica comparada. Minerva Coimbra, 2008.

SANCHO, J. L. V. La Infografia: Técnicas, Análisis y Usos Periodísticos. Universitat Autònoma de Barcelona, Bellaterra, 2001.

SCHMITT, V. A Infografia Jornalística na Ciência e Tecnologia. Um experimento com estudantes de jornalismo da Universidade Federal de Santa Catarina. Dissertação (Engenharia e Gestão do 
Conhecimento). Florianópolis: UFSC - Universidade Federal de Santa Catarina, 2006.

SEGEL E.; Heer, J. Narrative Visualization: Telling stories with data, IEEE Transactions on Visualization and Computer Graphics, 16(6), 2010.

TEIXEIRA, T. Infografia e Jornalismo: conceitos, análise e perspectivas. Salvador: EDUFBA, 2010.

TUFTE, E. The visual display of quantitative information. Connecticut: Graphic Press, 2001.

TVERSKY, B.; MORRISON, J. B.; BETRANCOURT, M. Animation: Can it facilitate? International Journal of Human-Computer Studies, 57(4), 2002.

WEBSTER, J.; WATSON, J. Analyzing the past to prepare for the future: writing a literature review. MIS Quarterly \& The Society for Information Management, v.26, n.2, pp.13-23, 2002. 